\title{
AC Impedance Responses of the Inconel 718 Alloy During Electropolishing in Perchloric-Acetic Mixed Acids
}

\author{
Ching An Huang ${ }^{1,2,3, *}$, Jhih You Chen ${ }^{1}$, Shu Wei Yang ${ }^{1}$ \\ ${ }^{1}$ Department of Mechanical Engineering, Chang Gung University, Taoyuan, Taiwan \\ ${ }^{2}$ Department of Mechanical Engineering, Ming Chi University of Technology, New Taipei, Taiwan \\ ${ }^{3}$ Bone and Joint Research Center, Chang Gung Memorial Hospital, Taoyuan, Taiwan \\ E-mail: gfehu@mail.cgu.edu.tw
}

doi: $10.20964 / 2017.04 .68$

Received: 10 August 2016 / Accepted: 25 November 2016 / Published: 12 March 2017

\begin{abstract}
The electropolishing behavior of Inconel 718 alloy was studied with an alternating current (AC) impedance test at $25^{\circ} \mathrm{C}$ in perchloric-acetic mixed acids with different $\mathrm{HClO}_{4}$ contents. The AC impedance test was conducted by polarizing a potential located in the limiting-current plateau with four potential amplitudes of 20, 200, 500, and $1000 \mathrm{mV}$. Experimental results show that the electropolishing behavior of Inconel 718 alloy depends strongly on the $\mathrm{HClO}_{4}$ content in the mixed acids. Leveling and brightening of the surface was obtained when Inconel 718 was polished in mixed acids with 30 and 40 volume percents of $\mathrm{HClO}_{4}$, while leveling without brightening of the surface is achieved when Inconel 718 was polished in mixed acids with 10 and $20 \mathrm{vol} \% \mathrm{HClO}_{4}$. The electropolishing behavior of Inconel 718 alloy in mixed acids can be recognized from its AC impedance response. Based on the results of AC impedance test, the electropolishing mechanism of Inconel 718 in the mixed acids follows the salt-film precipitated mechanism. A high potential amplitude from 200 to $500 \mathrm{mV}$ is recommended for obtaining a stable AC impedance response based on our experimental results, those contrast the generally accepted potential amplitudes lower than 20 $\mathrm{mV}$ used in the AC impedance test. Differences in stable and unstable AC impedance responses with respect to the potential amplitude are discussed in this study.
\end{abstract}

Keywords: Inconel 718 alloy, electropolishing, AC impedance test, potential amplitude

\section{$\underline{\text { FULL TEXT }}$}

(C) 2017 The Authors. Published by ESG (www.electrochemsci.org). This article is an open access article distributed under the terms and conditions of the Creative Commons Attribution license (http://creativecommons.org/licenses/by/4.0/). 